\title{
13. Crisis leadership in terra incognita: why meaning making is not enough
}

\author{
Arjen Boin
}

\section{Managing a financial tsunami}

The global financial crisis that started some time in 2007 and continues to unfold is a pure example of a trans-boundary crisis: it washes over geographical boundaries and leaves no sector of economic and social life untouched. It is hideously complex and thus hard to map and comprehend; it escalates through 'tipping points' and rides reversed feedback loops. The damage is staggeringly high and mounting. The 'new normal' that will emerge after this crisis will likely look very different from the one we had before.

Comparisons with the depression years of the 1930s often suggest the current crisis is not nearly as bad and is mostly under control, but the debate raging among economists tells a different story: nobody knows how bad it really is and what is still in store for us (for instance, Bradley et al. 2009). Economists disagree about how many toxic assets are still out there, what the consequences of worldwide stimulus packages will be, whether lost manufacturing jobs will ever return to Western economies and when it will be over. For political leaders, the global financial crisis is terra incognita.

How can political leaders navigate this unknown terrain? Traditional crisis-management skills - making 'hard calls' under pressure and with little information - are no longer sufficient according to crisis researchers. It is not just what they do or decide; what truly matters is what leaders say, the way they say it and the way it is understood by others. Great crisis leaders - Abraham Lincoln, Franklin D. Roosevelt, Winston Churchill and John F. Kennedy - are remembered for their eloquence and their words of consolation and inspiration when it mattered most.

In the early months of his presidency, Barack Obama was frequently referred to as the 'cheerleader in chief' and the 'psychologist in chief' (tellingly, perhaps, it remained unclear who the 'economist in chief' was). The US President was chastised alternately as being 'too pessimistic' and 'naively optimistic'. The attitude and words of leaders still matter a great deal in times of crisis.

Crisis leadership, in this perspective, is essentially about the use of discourse aimed at shaping a shared understanding of adverse events and providing guidance for dealing with them ('t Hart 1993). The underlying assumption is 
that incumbent elites try to frame the events and persuade the public (through the media) to accept their definition of the situation. The hypothesis is that a well-executed meaning-making strategy will help win the framing contest and thus shore up political capital and the policy commitments of leaders (Boin et al. 2009).

\section{Management by discourse: does it work?}

How did leaders fare during the global financial crisis? Surprisingly, perhaps, most survived the period under study; there were a few changes in the ruling party following elections held during the crisis, but it is not clear how the electoral outcomes relate to the actual management of the crisis. The lasting impression that emerges from this book, however, is of a group of leaders that stumbled and fumbled in their pursuit of an ever-escalating crisis.

The starting position of all leaders was similar: they downplayed or denied that there was a crisis. They thus placed the burden on those who sought to convince the public that there was a crisis. This initial defensive position would greatly limit their room for rhetorical manoeuvring.

In their subsequent descriptions of the evolving crisis, the leaders under study used very similar wordings: they pointed to 'outside forces' and spoke of 'very challenging', 'unprecedented' times - the 'worst since the Great Depression'. They admonished people not to panic: 'we are well placed' to manage these times, much better than other countries, as 'the fundamentals of our economy are strong'. And, of course, they promised that 'we will come out better than we were'.

They also displayed a strong tendency to moralise: many could not resist the temptation to blame the US system (US leaders, in turn, could not hide a hint of satisfaction when the European economies took a nosedive). When more and more financial institutions disclosed their 'toxic assets', the blame quickly shifted to greedy banks and their bankers.

The leaders seemed constantly behind the curve: by the time they recognised that there was a crisis, it had already spun out of control. After they failed to 'talk up the economy', they failed to 'talk down the crisis'. When they were finally ready to admit that the situation was bad, they were forced to emphasise how strong 'the fundamentals' were in fear of adding fuel to the fire.

An intriguing observation of this book is that the selected media apparently showed little interest in the speech acts of these leaders. The newspapers, in other words, did not recognise any news value in the meaning-making efforts of political leaders.

This could mean that leaders 'make meaning' through different media-local media, television and the Internet - or in different venues (parliamentary debates, 
informal conversations, op-ed pieces). It could also mean that leaders were not trying very hard to offer a distinct interpretation of events - one that would deviate from the tired rhetoric described above and would therefore generate 'news'.

A reading of the chapters suggests that leaders were caught in a prisoner's dilemma. If all leaders are trying to make meaning of the same event, it becomes dangerous to offer radically different interpretations (especially if everyone is aware that their statements can directly affect the process of crisis escalation). Timely and realistic assessments of existing vulnerabilities, evolving problems and escalating downturns can, after all, chase away investors, drive down the currency and sink the stock markets.

\section{Crisis exploitation: how, then, does one exploit a global crisis?}

US presidential candidate Obama used the evolving crisis to his advantage, attacking his opponent, John McCain, for declaring repeatedly that the 'fundamentals of our economy are strong'. Obama did not, however, win the election on a bad economy alone. Moreover, President Obama found it hard to exploit the crisis to further his political agenda (his stimulus bill was watered down considerably to please Republicans). If anything, the continuing crisis is seriously hampering his reform objectives (think of a new health system or a greener climate).

The global financial crisis did come in handy for those leaders who were already facing an economic downturn due to longstanding vulnerabilities. Those leaders were relatively quick to recognise the global financial crisis, making sure to stress its 'unprecedented' and exogenous nature. In a similar vein, we can conclude that the global financial crisis relieved some leaders of the responsibility for dealing with complex policy problems that could now be branded 'unaffordable under the current circumstances'. While all this can be categorised as a form of crisis exploitation, it has little to do with the timely use of 'opportunity windows' (Kingdon 1997) to push through otherwise unpalatable or infeasible reforms.

The dearth of targeted and timely reforms in the wake of a global crisis - supposedly a great time for deep reform (Hall 1993)-suggests crisis exploitation might be harder or less prevalent than theory sometimes suggests it is (Kingdon 1997). In spite of cheerful comments that a 'good crisis should not be wasted' ('il faut utiliser une crise'), few fundamental proposals were successfully initiated to redesign the financial system.

The idea that leaders can and do exploit crises to further their political interests thus merits renewed scrutiny (cf. Boin and 't Hart 2000). A successful effort would require a serious understanding of crisis dynamics; leaders would have 
to grasp how and why these crises escalate and what they can do to arrest the process. Moreover, they must have a firm grasp of the way journalists, opposition leaders and interested citizens perceive and assess their frames and actions. They would have to persuade people that they could shift a crashing economy this or that way.

This book shows that crisis exploitation is not without risks. Leaders who try can become caught in so-called credibility gaps. For instance, emphasising external causes might divert attention from home-grown failures, but it also undermines the legitimacy of subsequent reform proposals. Overplaying the crisis to push through a reform package can create expectations that the proposed reforms cannot meet. Botched efforts to exploit a crisis might fuel public cynicism with regard to the functioning and performance of the political system.

\section{Reconsidering crisis leadership}

Lest we become too gloomy about the prospects for crisis leadership, we should perhaps apply a wider and more balanced leadership perspective. In the introductory chapter, the editors helpfully define crisis leadership in terms of nine challenges (meaning making is only one of them). The global financial crisis - still in full swing at the time of writing - has tested world leaders on the first five: the challenges of sense making, meaning making, decision making, coordination and delimitation. Apart from meaning making (discussed above), how did leaders perform on those other four challenges?

Perhaps one of the most glaring failures of global leaders - and especially US leaders - is found in the sense-making domain. 'The field of economics is anything but an exact science,' 't Hart and Tindall correctly note in the introductory chapter. At the same time, no $\mathrm{PhD}$ in economics was required to recognise that the US economy was bound to run into serious trouble. Indeed, many journalists mapped the deep vulnerabilities as far back as 2005. When the economy was spiralling into recession, former President Bush and Senator McCain continued their talk of 'strong fundamentals'.

It took leaders of all countries a remarkably long time to diagnose the situation correctly. Hindsight does not make this assessment harder than it perhaps should be. The knowledge - as any analysis of op-ed pages, economic headlines and serious news reports will confirm - was widely available. One would have to conclude that leaders did not want to acknowledge or confirm an uncomfortable and inconvenient truth.

Leaders performed much better when it came to critical decision making. Once the extent of the potential damage had become undeniable, leaders acted with remarkable speed and courage. US leaders infused the system with unprecedented sums of money after the failure of the Lehman Brothers Bank threatened to take the system down in September 2008. 'If we don't do this, we may not have an 
economy on Monday,' Federal Reserve Chairman, Ben Bernanke, reportedly told US law-makers (Nocera 2008). This was only one of the many drastic decisions taken across the world. It serves as a reminder that decision making is still a critical part of the crisis leadership package. ${ }^{l}$

A global crisis that cascades across policy boundaries requires crisis coordination. This has traditionally been viewed as somewhat of a holy grail: it is hard in good times and nearly impossible in bad times - or so the thinking goes (Boin et al. 2005). It was thus impressive to see the level of coordination that was achieved across sectors, administrations (the remarkable cooperation between the outgoing Bush Administration and the incoming Obama Administration) and between countries. The role of international organisations such as the International Monetary Fund (IMF), the World Bank and the European Union grew quickly and with little controversy.

It is hard to prove, but leaders seemed much less adept at managing expectations (the challenge of delimitation). With few exceptions (such as Singapore's leader), leaders consistently avoided telling the public flat-out that an economic crisis of this size and scope would drag down a society's level of wellbeing. (Compare this with the frank talk delivered by US President Roosevelt in his 'fire-side chats'; 'Yes, we shall have to give up many things entirely,' Roosevelt told his fellow countrymen after declaring war on Japan in December 1941.) The hardest-hit countries will have to learn to live within their means. That usually means more taxes and less government spending. The rhetoric of world leaders - as analysed in this book - suggests nothing of the kind.

Taken together, it would seem that leaders are better at doing than talking during a crisis. They find it hard to admit a crisis has arrived. Their crisis rhetoric is often bland and cliché ridden, as this book documents so well. And, when they finally address the crisis, leaders shun the cold, hard truth.

What can we learn in terms of trans-boundary crisis management? As the classic tasks of crisis management at first glance appear to have been fulfilled reasonably well, most mileage can be gained from an improvement of early warning and sense-making capacities. This crisis had all the markings of an announced crisis. The key question, once again, is therefore: why did they not see it coming (Turner 1978)?

A preoccupation with the functional dimensions of crisis management - getting a clear picture of the situation, making critical decisions, coordinating multiple parties - has long prevented crisis scholars from recognising the importance of the symbolic dimension of crisis management. This book demonstrates how far crisis researchers have come. This empirical study also signals the limits of meaning making: the inescapable conclusion is that the management of crisis symbolism is not enough; trans-boundary crises demand the full execution of all crisis tasks. 
Framing the global economic downturn

\section{References}

Boin, A. and 't Hart, P. 2000, 'Institutional crises in policy sectors: an exploration of characteristics, conditions and consequences', in H. Wagenaar (ed.), Government Institutions: Effects, changes and normative foundations, Kluwer Press, Boston, pp. 9-31.

Boin, A., 't Hart, P., Stern, E. and Sundelius, B. 2005, The Politics of Crisis Management: Public leadership under pressure, Cambridge University Press, Cambridge.

Boin, A., McConnell, A. and 't Hart, P. 2009, 'Crisis exploitation: political and policy impacts of framing contests', Journal of European Public Policy, vol. 16, no. 1, pp. 81-106.

Bradley, B., Ferguson, N., Krugman, P., Roubini, N., Soros, G. and Wells, R. 2009, 'The crisis and how to deal with it', The New York Review of Books, vol. 56, no. 10 (11 June).

Hall, P. 1993, 'Policy paradigms, social learning, and the state: the case of economic policymaking in Britain', Comparative Politics, vol. 25, no. 3, pp. 275-96.

't Hart, P. 1993, 'Symbols, rituals and power: the lost dimension in crisis management', Journal of Contingencies and Crisis Management, vol. 1 no. 1, pp. 36-50.

Kingdon, J. W. 1997, Agendas, Alternatives and Public Policies, $2^{\text {nd }}$ edn, Pearson, Upper Saddle River, NJ.

Nocera, J. 2008, 'The reckoning: a credit crisis spiraled, alarm led to action', The New York Times, 1 October.

Stern, E. and Sundelius, B. 1997, 'Sweden's twin monetary crises of 1992: rigidity and learning in crisis decision making', Journal of Contingencies and Crisis Management, vol. 5, no. 1, pp. 32-48.

Turner, B. A. 1978, Man-Made Disasters, Wykeham, London.

\section{Endnotes}

${ }^{1}$ For a similar description of drastic crisis decision making in the Swedish financial crisis of 1992, see Stern and Sundelius (1997). 